\title{
Simulación virtual de brote epidémico en una unidad de diálisis
}

Purificación Jiménez Jaén - Lili Ana Maldonado López - María Ángeles Gras Baeza - María Aurelia Puerto Pérez - Francisco Javier Gallego González-Aller - Yolanda Quintero Pérez

Unidad de Diálisis. Hospital Comarcal de Melilla

\section{Sra. Directora:}

Los pacientes renales en programa de hemodiálisis presentan una inmunidad deprimida y una mayor susceptibilidad a las infecciones. La necesidad de manipular un punto de acceso vascular y de realizar varias sesiones semanales de circulación extracorpórea de varias horas de duración, a través de un circuito con puntos permeables a virus y bacterias, aumenta la vulnerabilidad de estos pacientes a la infección por microorganismos que contaminan los objetos existentes en su entorno próximo, incluyendo los propios monitores.

La epidemiología de las infecciones por virus transmitidos por la sangre en los pacientes que requieren hemodiálisis intermitente sigue siendo desconocida en buena medida y no se sabe con exactitud como se transmiten virus como el VHC a los pacientes en diálisis, lo que supone un riesgo constante en las modernas unidades de diálisis. El contagio de los virus es objeto de especial preocupación desde el punto de vista de la enfermería preventiva. Las posibles medidas para prevenir la transmisión de estos virus son actualmente objeto de controversia.

La Teoría de Grafos y el Análisis de Redes Sociales son herramientas matemáticas altamente sofisticadas que requieren recursos informáticos complejos y que se emplean desde épocas relativamente recientes en estudios epidemiológicos. Esta nueva metodología permite analizar la estructura y variaciones temporales de las redes de contagio.

\begin{tabular}{|c|}
\hline Correspondencia: \\
Purificación Jiménez Jaén \\
Unidad de Diálisis \\
Hospital Comarcal de Melilla \\
Remonta 2 \\
52005 Melilla \\
puri@osmanet.com
\end{tabular}

El objetivo de este trabajo es analizar las características estructurales de la red de transmisión cruzada durante la diálisis de un germen potencialmente capaz de contaminar una máquina de diálisis y contagiar a otros pacientes. El estudio pretende identificar y cuantificar el riesgo de exposición a gérmenes transmisibles en 2 situaciones:

- Asignación preferente pero flexible de la misma máquina a cada paciente en las sucesivas sesiones de diálisis

- Asignación estricta de la misma máquina a cada paciente en las sucesivas sesiones de diálisis

El estudio se llevó a cabo en 2 fases (62 pacientes en diciembre de 2007 y 71 pacientes en junio de 2008 respectivamente) en la unidad de diálisis de un hospital comarcal, dotado de 19 máquinas de diálisis.

Para llevar a cabo la simulación se eligió en cada fase, y de forma aleatoria, a uno de los pacientes, al que se consideró portador de un agente infeccioso potencialmente capaz de transmitirse entre pacientes, mediante el empleo compartido de una misma máquina de diálisis. En cada fase, y durante 10 días consecutivos (excluyendo los domingos), se registraron las maquinas asignadas a todos los pacientes en cada sesión de diálisis.

En la primera fase del estudio, los pacientes fueron dializados de forma preferente con la misma máquina aunque tal asignación se aplicó con cierta flexibilidad, de forma que se realizaron algunos cambios en la asignación paciente-máquina para hacer frente a incidencias rutinarias relacionadas con el funcionamiento del servicio, la presión asistencial, las necesidades clínicas y la comodidad de los pacientes. En la segunda fase del estudio, se llevó a cabo una asignación estricta de la misma máquina para cada paciente en todas las sesiones de diálisis. 
Con las parejas de asignación paciente-máquina se elaboraron matrices direccionales de co-ocurrencia que se analizaron mediante el programa UCINET 6.1 § y se diseñaron representaciones gráficas que permiten visualizar la red de pacientes y máquinas expuestas cada día al contagio del agente infeccioso simulado.

Las redes sociales están configuradas por 2 elementos básicos: nodos y vínculos, que definen la relación existente entre los nodos. En este estudio, los pacientes y las máquinas son los "nodos" de la red, y el "vínculo" (link) que los relaciona es el contacto en una sesión de diálisis. Las representaciones gráficas o grafos generados por una red de contagio permiten visualizar de forma comprensible las relaciones entre los individuos afectados y su estructura, componentes y subgrupos.

Para la comparación de proporciones de pacientes y máquinas expuestos en cada muestra se realizó test de chi $^{2}$ de Pearson, admitiéndose la significación estadística para valores de $p<0,05$.

En la primera fase de la simulación (asignación máquina - paciente preferente pero flexible), 54 de los 62 pacientes $(87,09 \%)$ podrían haberse visto expuestos al contagio, y 13 de las 19 máquinas $(68,42$ $\%$ ) podrían haberse contaminado (figura 1). En la segunda fase del estudio (asignación estricta máquina - paciente), se vieron expuestos 5 de 71 pacientes $(7,05 \%)$ y sólo 1 de las 19 máquinas $(5,26 \%$ ) (figura 2). La comparación de estos porcentajes mediante el test de $\mathrm{chi}^{2}$ de Pearson mostró diferencias significativas (tabla 1 ).

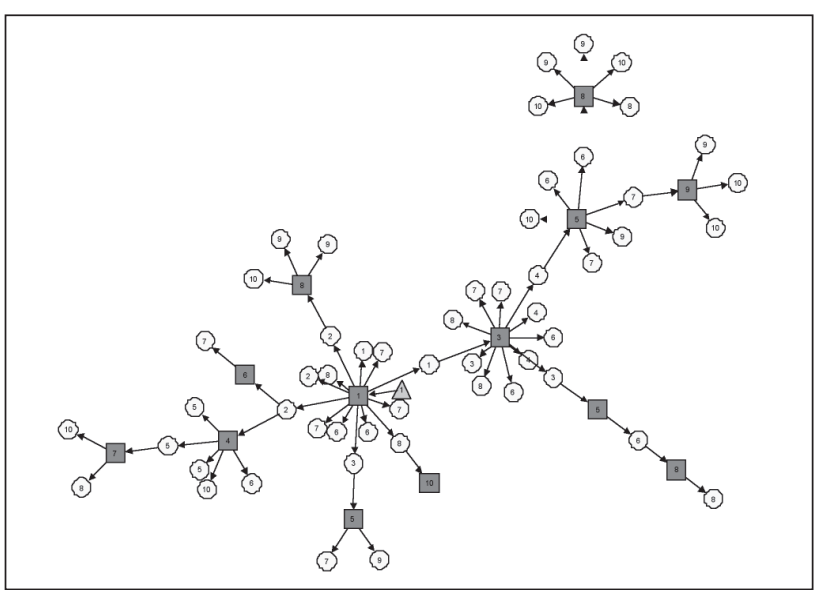

Figura 1. Red de exposición al contagio en el modelo de asignación flexible de máquinas de diálisis a pacientes. En número inscrito en el interior de cada nodo designa el día en que ocurre la exposición.

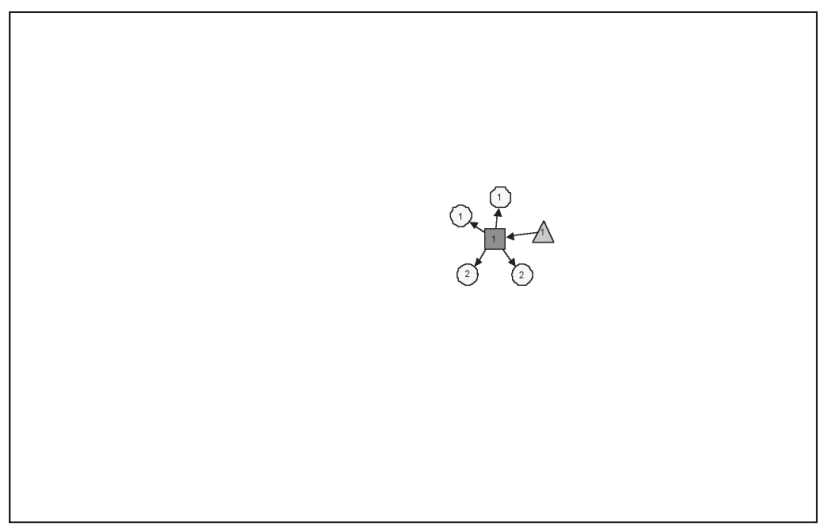

Figura 2. Red de exposición al contagio en el modelo de asignación estricta de máquinas de diálisis a pacientes. En número inscrito en el interior de cada nodo designa el día en que ocurre la exposición.

\begin{tabular}{|c|c|c|c|c|c|}
\hline \multirow{3}{*}{ PACIENTES } & \multirow{3}{*}{\begin{tabular}{|l} 
ASIGNACION \\
FLEXIBLE \\
ASIGNACION \\
ESTRICTA
\end{tabular}} & EXPUESTOS & $\begin{array}{l}\text { NO } \\
\text { EXPUESTOS }\end{array}$ & $\begin{array}{l}\text { \% } \\
\text { EXPOSICIÓN }\end{array}$ & $\mathrm{p}$ \\
\hline & & 54 & 8 & 87,09 & \multirow{2}{*}{$<0,01$} \\
\hline & & 5 & 66 & 7,05 & \\
\hline \multirow{3}{*}{$\begin{array}{l}\text { MÁQUINAS } \\
\text { DE } \\
\text { DIÁLISIS }\end{array}$} & & EXPUESTAS & $\begin{array}{l}\text { NO } \\
\text { EXPUESTAS }\end{array}$ & $\begin{array}{l}\% \\
\text { EXPOSICIÓN }\end{array}$ & $p$ \\
\hline & $\begin{array}{l}\text { ASIGNACIÓN } \\
\text { FLEXIBLE }\end{array}$ & 13 & 6 & 68,42 & \multirow{2}{*}{$<0,01$} \\
\hline & $\begin{array}{l}\text { ASIGNACIÓN } \\
\text { ESTRICTA }\end{array}$ & 1 & 18 & 5,26 & \\
\hline
\end{tabular}

Tabla 1. Proporciones de pacientes y máquinas expuestos a la transmisión en los modelos de asignación flexible y asignación estricta de máquinas a pacientes

Las recomendaciones para evitar la transmisión de enfermedades virales en unidades de diálisis establecidas en las guías clínicas más utilizadas se resumen en la tabla 2.

\begin{tabular}{|l|l|l|l|}
\hline & HIV & VHB & VHC \\
\hline $\begin{array}{l}\text { MONITORES } \\
\text { EXCLUSIVOS }\end{array}$ & NO & SI & $\begin{array}{l}\text { CDC (2001): NO } \\
\text { SEN (2006): NO } \\
\text { KDIGO (2008): NO }\end{array}$ \\
\hline $\begin{array}{l}\text { PERSONAL } \\
\text { EXCLUSIV0 }\end{array}$ & NO & SI & $\begin{array}{l}\text { CDC (2001): NO } \\
\text { SEN (2006): PACIENTES CON PCR + } \\
\text { KDIGO (2008): NO }\end{array}$ \\
\hline $\begin{array}{l}\text { AISLAMIENTO } \\
\text { FÍSICO }\end{array}$ & NO & SI & $\begin{array}{l}\text { CDC (2001): NO } \\
\text { EBPG (2002): UNIDADES CON ALTA } \\
\text { PREVALENCIA } \\
\text { SEN (2006): PACIENTES CON PCR + } \\
\text { KDIGO (2008): NO }\end{array}$ \\
\hline
\end{tabular}

$C D C=$ Centers for Desease Control

SEN = Sociedad Española de Nefrología

KDIGO = Kidney Internacional Disease Improving Global Outcomes

$E B P G=$ European Best Practice Guidelines

Tabla 2. Medidas recomendadas para la prevención de la transmisión de virus en unidades de diálisis. 
Los pacientes sometidos a hemodiálisis requieren una elevada carga de trabajo de enfermería durante las 4 horas que dura aproximadamente cada sesión. La manipulación de las máquinas de diálisis y de los pacientes por el personal de enfermería podría desempeñar algún papel en la transmisión nosocomial de infecciones. Existe una relación entre la infradotación de personal en las unidades de diálisis y la transmisión de virus entre los pacientes dializados, por lo que la SEN recomienda una dotación mínima de 1 enfermero/a por cada 4-5 puestos y 1 auxiliar por cada 8-10 puestos. Por el momento, la forma más eficaz de prevenir la transmisión horizontal de gérmenes en una unidad de diálisis es la aplicación de estrictas medidas de higiene por el personal responsable.

Por tanto, en una unidad de diálisis es posible la presencia de un paciente infectado por un germen capaz de transmitirse a otros pacientes a través de la contaminación incidental de la máquina de diálisis (por ejemplo, un caso no detectado de infección por VHB).

La práctica de asignar máquinas diferentes a un mismo paciente en las sucesivas sesiones favorece la propagación del riesgo a la contaminación de otras máquinas y pacientes. La asignación estricta de una misma máquina a cada paciente en todas las sesiones de diálisis minimiza significativamente este riesgo de exposición al contagio.

\section{Bibliografía}

1. Centers for Desease Control and Prevention. Recommendations for Preventing Transmission of Infections among Chronic Hemodialysis Patients. MMWR. 2001; 50:18-30.

2. European Best Practice Guidelines for Haemodialysis (Part 1). Nephrol Dial Transplant. 2002; 17(Suppl 7):79-80.

3. KDIGO Clinical Practice Guidelines for the Prevention, Diagnosis, Evaluation, and Treatment of Hepatitis C in Chronic Kidney Disease. Guideline 3: Preventing HCV transmission in hemodialysis units. Kidney Int. 2008; 73 (Suppl 109):46-52.

4. Otero A, Conde J, Martín de Francisco AL, Gonzáles Parra E. Guías de Centros de Hemodiálisis (SEN). Introducción. Nefrología 2006; 26(Supl)8:1-4.

5. Sanz L. Análisis de Redes Sociales: o como representar las estructuras sociales subyacentes. Apuntes de Ciencia y Tecnología 2003; 7:21-9. 